\title{
Short-Term Administration of Melatonin or Ghrelin on Diabetic Rats: Effects on Angiotensin II and Vasopressin-Induced Uterine Contractility
}

\author{
T. GEORGIEV ${ }^{1}$, A. TOLEKOVA ${ }^{1}$, R. KALFIN ${ }^{2}$, P. HADZHIBOZHEVA ${ }^{1}$ \\ ${ }^{1}$ Department of Physiology, Pathophysiology and Pharmacology, Medical Faculty, Trakia \\ University, Stara Zagora, Bulgaria, ${ }^{2}$ Institute of Neurobiology, Bulgarian Academy of Sciences, \\ Sofia, Bulgaria
}

Received March 2, 2016

Accepted June 21, 2016

On-line October 26, 2016

\section{Summary}

The aim of the present study was to investigate the effects of Angiotensin II (Ang II) and Arginin-Vasopressin (AVP) on contractility of non-pregnant uterus in diabetic Wistar rats and to explore whether one-week administration of Melatonin (MLT) or Ghrelin (GHR) will change the response of diabetic uterine muscle to AngII and AVP. Uterine horns, prepared by the method of isolated tissues were investigated as well as glycemic profile, blood pressure and body weight. The research of smooth muscle contractions was made by a new method of analysis, characterizing in detail the various phases of the myometrial activity. Differences in the development of the peptide-mediated smooth muscle contractions depending on the phase of the estrous cycle were observed. Experimental diabetes had a pronounced negative effect on force and time-parameters of AngII and AVP-stimulated uterine contractions. Administration of GHR or MLT had a beneficial effect on the glycemic status of diabetic rats and partially improved the response of uterine preparations to the peptides. The application of MLT increased both force and time-parameters of Ang II-and AVP-stimulated uterine contractions while treatment with GHR increased power characteristics and shortened contraction and relaxation of the smooth muscle process.

\section{Key words}

Diabetes • Mellitus • Uterine contraction • Peptides • Ghrelin • Melatonin

\section{Corresponding author}

T. Georgiev, Department of Physiology, Pathophysiology and
Pharmacology, Medical Faculty, Trakia University, 11 Armeiska Street, Stara Zagora 6000, Bulgaria. E-mail: phript@gmail.com

\section{Introduction}

The disorders in uterine contractile activity are in the basis of a number of disturbances such as preterm deliveries, dysfunctional labor, postpartum hemorrhage, primary dysmenorrhea, etc. (Wray 2007). A better understanding of the mechanisms that lead to myometrial contractility and the humoral factors responsible for the regulation of the uterine tone is of an essential importance for the prophylaxis and treatment of these contractile uterine complications. Angiotensin II (Ang II) and Arginine-Vasopressin (AVP) are important factors in the regulation of the smooth muscle tone. They act in a similar pattern, by activating the inositol-triphosphate signal pathway. Besides the proven contractile effect of Ang II and AVP on the uterine arteries, the myometrium is also sensitive to the effect of these octapeptides (Keskil et al. 1999, Steinwall et al. 2005).

Diabetes mellitus (DM) comprises a group of metabolic disorders characterized by hyperglycemia due to disturbances in insulin secretion, insulin action, or both. The persistent hyperglycemia leads to long-term organ damages, thus affecting all the systems in the organism (Abu-El Asrar 2013). Most of the manifested symptoms of DM are related to smooth muscle dysfunction (Stamler et al. 1993). The etiology of the impaired smooth muscle motility in DM is multifactorial, 
assuming involvement of oxidative stress, apoptosis, neuronal loss, and accumulation of glycated products (Suzuki et al. 2011, Chang et al. 2012). Considering the role of oxidative stress for the development of structural and functional cell damage and the progression of DM, many scientific efforts are directed towards search and application of effective antioxidants (Chatzigeorgiu et al. 2009). Such possible antioxidants having a therapeutic potential for treatment of diabetic disorders, are hormones melatonin (MLT) and ghrelin (GHR). In rats with experimentally induced diabetes, it was found that administration of these hormones exerts a protective effect on pancreatic beta-cells mass and function (Vural et al. 2001, Granata et al. 2010).

The diabetic changes in Ang II- and AVP-mediated contractile activity of uterus are not enough studied (Falkay et al. 2007, Shpakov et al. 2013) as well as the effect of administration of MLT and GHR on myometrial smooth muscle activity.

The published data about effects of GHR on myometrial activity are controversial. Some authors found that GHR stimulates rat spontaneous uterine contractions (AlSaif et al. 2015). On the other hand, Hehir et al. (2008) have reported that GHR has concentration-dependent inhibitory effect on myometrial activity. For the duration of the pregnancy, the highest levels of GHR in serum (measured as total concentration) are detected in the mild-gestation period and the lowest in the last trimester (Hehir et al. 2008). It was also found that myometrially-produced GHR plays an important role in relaxation in this tissue during pregnancy (O'Brien $e t$ al. 2010). MLT also has significance for the timing and power of uterine contractions. It acts through MTNR1B receptor to increase oxytocin-dependent contractions in end-term pregnancy (Olcese and Beesley 2014).

The aim of this study is to investigate the effects of Ang II and AVP on myometrial smooth muscle of rats with experimentally induced diabetes and to explore whether one-week administration of MLT or GHR on diabetic rats will change the response of uterine smooth muscle of Ang II and AVP.

\section{Methods}

\section{Animals}

32 non-pregnant female Wistar rats, weighting 200-250 g were used. The animals were divided into the following groups: Group 1: controls; Group 2: diabetic animals; Group 3: diabetic animals, treated with MLT;
Group 4: diabetic animals treated with GHR. DM was induced by a single intraperitoneal injection of Streptozotocin (STZ) $60 \mathrm{mg} / \mathrm{kg}$ b.w. STZ was dissolved in cold $0.1 \mathrm{M}$ citrate buffer, $\mathrm{pH} 4.5 .72 \mathrm{~h}$ after STZ administration, only animals with blood glucose levels higher than $16 \mathrm{mmol} / \mathrm{l}$ were considered to be diabetic and left in the experiment. The experiment lasted 42 days. In the beginning and in the end of experimental period, body weight, glycated hemoglobin (HbAlc) and blood pressure of the animals were measured. In the end of the experimental period plasma levels of C-peptide were determined.

GHR was administered in dose of $100 \mu \mathrm{g} / \mathrm{kg}$ s.c. (Granata et al. 2010). The application of GHR started in the next day, after STZ injection and lasted 7 consecutive days (Granata et al. 2010). MLT was administered in dose of $10 \mathrm{mg} / \mathrm{kg}$ i.p. (Vural et al. 2001). The application of MLT started in the next day, after STZ injection and lasted 7 consecutive days. The control group was injected with saline i.p. for 8 consecutive days.

\section{Sample preparations and experimental protocols}

In the end of experimental period, animals were anesthetized with Nembutal $50 \mathrm{mg} / \mathrm{kg}$ i.p. and preparations of uterine horns $(\mathrm{UH})$ were made. Immediately prior to anesthesia, vaginal smears were obtained in order to determine the phase of estrous cycle and to assess a possible influence of sex hormones on uterine activity (Aguilar and Mitchell 2010). The experimental protocol of the study was approved by the Institutional Animal Care and was in accordance with the national regulations and European Directive of 22.09.2010 (210/63/EU) concerning the protection of animals used for scientific and experimental purposes.

The preparation of the tissue samples and the recording of mechanical activity were conducted as it was previously described (Tolekova et al. 2010, Georgiev et al. 2012). After the equilibration period, preparations were influenced by Ang II or AVP in a dose of $1 \mu \mathrm{mol}$ $\left(10^{-6} \mathrm{M}\right)$.

\section{Chemicals, drugs and equipment}

Ang II, AVP, STZ, MLT and all reagents for preparation of Krebs solution and citrate buffer were purchased from Sigma-Aldrich Chemie GmbH, Germany. GHR was purchased from PolyPeptide Group, Sweden. HbA1c was determined by Glycohemoglobin HbA1-test (HUMAN, Germany). Blood glucose levels were measured by Medisign mm810 glucometer (Empecs 
Medical Device Co., Ltd., China). The system for noninvasively measuring the blood pressure of rats was purchased from BIOPAC Systems Inc., USA.

\section{Data analysis and statistical processing}

The mechanical activity was transformed by mechanical-force sensor, amplified, digitized and recorded using digital acquisition software ISOSYSADVANCED 1.0, produced by Experimetria Ltd., Hungary. The conversion of the data and primary data processing was performed with KORELIA-Processing software (Yankov 2010). The recorded force-vs.-time curves permit determination of amplitudes of contraction and integrated force of contraction (represented by the area under the curve - AUC). The following timeparameters of smooth muscle contraction (SMC) were defined and calculated: half-contraction time $\left(\mathrm{T}_{\mathrm{hc}}\right)$ - time interval between the beginning of SMC and half of the maximal force $(F \max / 2)$; contraction time $\left(\mathrm{T}_{\mathrm{c}}\right)$ - time interval between the beginning of SMC and Fmax; halfrelaxation time $\left(\mathrm{T}_{\mathrm{hr}}\right)$ - time interval between Fmax and Fmax/2; contraction plus half-relaxation time $\left(\mathrm{T}_{\text {chr }}\right)$ - time interval between the start of the SMC and Fmax/2. The duration of interval for analysis of tonic contraction was $5 \mathrm{~min}$. Reported amplitudes, integrated force and time-parameters of uterine SMC were analyzed with KORELIA-Dynamics software (Yankov 2012).

Obtained data were processed by the statistical program Statistica Version 6.1 (StaSoft, Inc., Tulsa, OK, USA) and presented as mean \pm standard error. Statistical analysis was performed using one-way ANOVA and Student $t$-test to determine significant differences among data groups. A $P$-value less than or equal to 0.05 was considered to be statistically significant.

\section{Results}

Regarding the amplitude of Ang II - provoked SMCs there were significant differences between contractions from preparations of the different phases as well as the different diabetic groups (Fig. 1). In phase 1 (follicular), all groups of preparations demonstrated significantly higher amplitude compared to those form phase 2 (luteal). The preparations from group 2 responded to Ang II with decreased amplitude compared to the controls $(3.62 \pm 0.59 \mathrm{~g}$ vs. $5.80 \pm 0.30 \mathrm{~g}$ in phase 1 and $1.12 \pm 0.18 \mathrm{~g}$ vs. $2.62 \pm 0.22 \mathrm{~g}$ in phase 2). It is interesting that uterine contractions from groups 3 and 4 were with similar amplitudes.

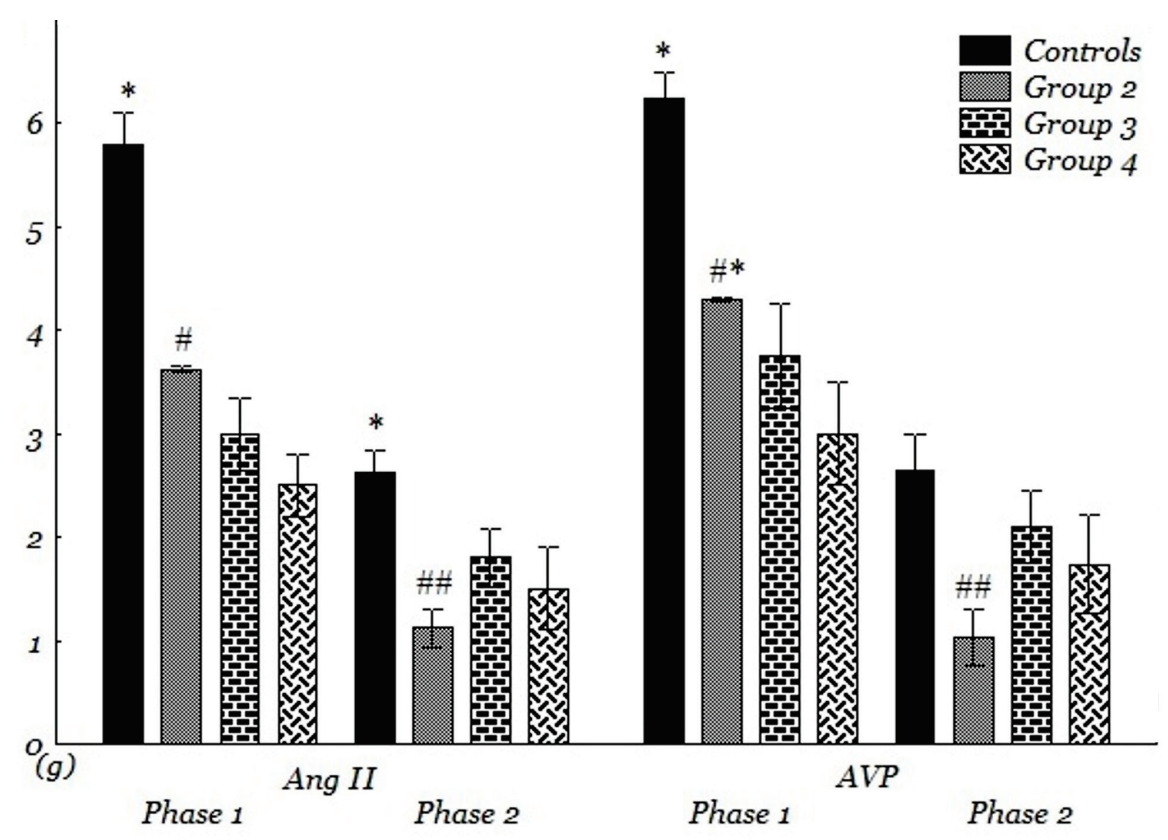

Fig. 1. Amplitude of Ang II- and AVP - provoked uterine contractions after inducing diabetes mellitus, with and without protection. Phase 1: folicular phase of estrous cycle; Phase 2: luteal phase of estrous cycle. Controls: healthy animals; Group 2: diabetic animals; Group 3: diabetic animals treated with MLT; Group 4: diabetic animals treated with GHR. * $P<0.05$ vs. groups $2-4,{ }^{\#} P<0.05$ vs. controls and groups 3 and 4 , $\# \# P<0.05$ vs. controls and group 3, \#* $P<0.05$ vs. controls and group 4.
In regard to amplitudes of AVP-induced SMCs, there was similar tendency in the response. Again, in both phases of the estrous cycle, the UH preparations from group 2 developed lower amplitude compared to those of the controls.
The analysis of the integral force of SMC obtained after application of Ang II revealed differences between the control group and the three diabetic groups (Fig. 2). During phase 1, AUC of Ang II-influenced contractions of preparations from diabetic groups were 
almost threefold decreased when compared to controls. In phase 2 this difference fell to twice. It is interesting to note that AUC of Ang II-induced contractions of group 3 showed no differences associated with the phase of estrous cycle $(443 \pm 35$ g.s for phase 1 and $434 \pm 31$ g.s for phase 2).

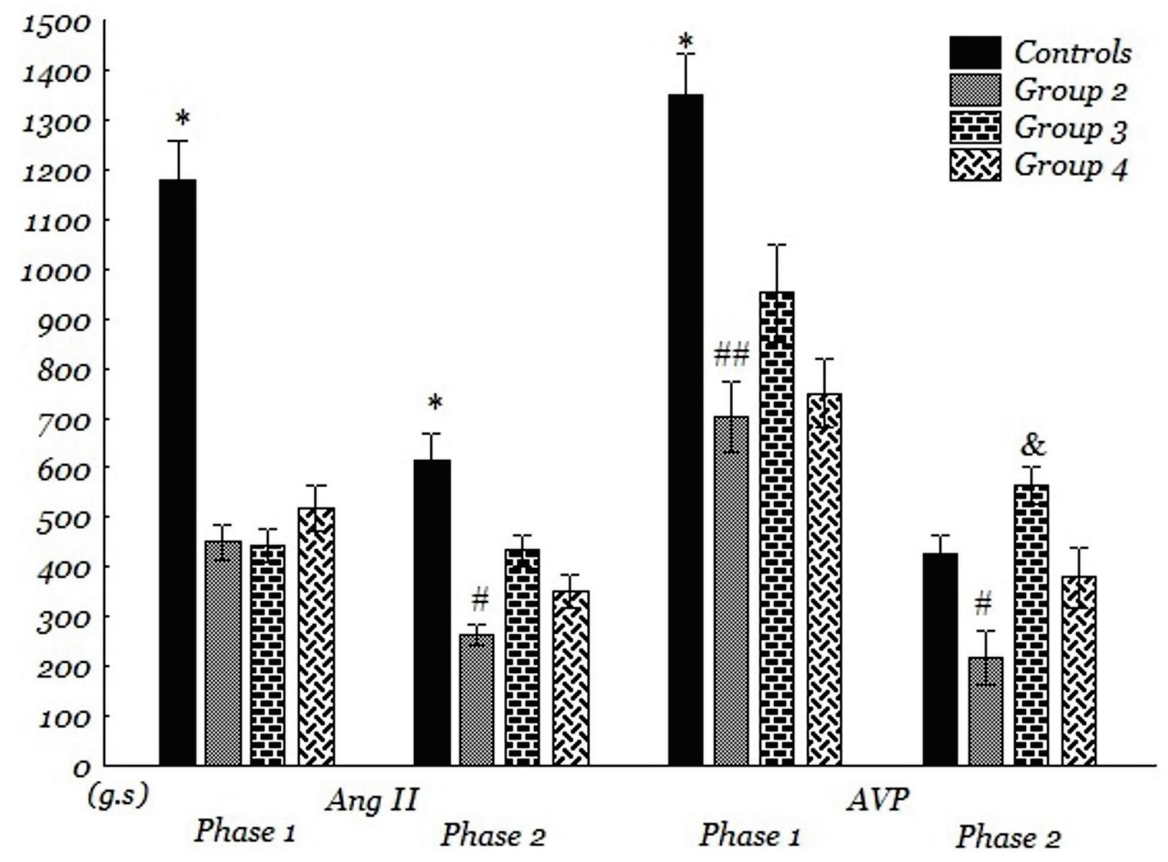

Fig. 2. AUC of Ang II- and AVP - provoked uterine contractions after inducing diabetes mellitus, with and without protection. Phase 1: folicular phase of estrous cycle; Phase 2: luteal phase of estrous cycle. Controls: healthy animals; Group 2: diabetic animals; Group 3: diabetic animals treated with MLT; Group 4: diabetic animals treated with GHR. * $P<0.05$ vs. groups $2-4,{ }^{\#} P<0.05$ vs. controls and groups 3 and 4 , \#\# $P<0.05$ vs. controls and group 3, \& $P<0.05$ vs. controls and groups 2 and 4.
The analysis of AUC of SMCs obtained after administration of AVP, also revealed similarities with AUC of Ang II-mediated contractions. During the phase 2, again preparations from group 2 developed weakest AUC - 218 \pm 54 g.s, preparations from group 3, however, developed contractions with greatest AUC $-564 \pm 36$ g.s. During the phase 1, the preparations of control group demonstrated the biggest AUC that was statistically different when compared to AUC of the other groups.

With respect to time-parameters of SMCs (Table 1) different results were obtained depending on the phases of the estrous cycle.

During phase 2 the preparations from group 2 and group 3 developed Ang II-provoked contractions with similar $\mathrm{T}_{\mathrm{c}}$, while the contractions from group 4 showed shortest values for this parameter (11 $12 \mathrm{~s})$. Regarding $\mathrm{T}_{\mathrm{hr}}$ and $\mathrm{T}_{\text {chr }}$, groups 3 and 4 were with intermediate values compared to control group and group 2. During phase 1, group 4 displayed fastest $\mathrm{T}_{\mathrm{hr}}$ and $\mathrm{T}_{\text {chr. }}$. In another hand, group 2 showed a faster relaxation compared to controls, while the contractions from group 3 were with the longest relaxation.

Regarding time-parameters of AVP-provoked
SMCs, the preparations from phase 1 developed contractions with similar $\mathrm{T}_{\mathrm{hc}}$ and $\mathrm{T}_{\mathrm{c}}$ with the exception of group 4 (Table 1). UH preparations from group 3 had contractions with prolonged $\mathrm{T}_{\mathrm{hr}}$ and $\mathrm{T}_{\text {chr }}$. Group 2 and 4 had fastest relaxation. During phase 2 only contractions of preparations from group 4 were with significantly different parameters compared to the other groups.

\section{Other parameters}

During the experimental period, no change in the blood pressure of the diabetic animals was found with exception of group 3 which was with statistically higher values. Regarding body weight, the control group increased their mass with $40 \mathrm{~g}$, while group 2 lost about $75 \mathrm{~g}$. The animals from group 3 and 4 kept their body weight (Table 2).

The analysis of blood sugar levels revealed that group 3 and 4 had lower plasma glucose levels than group 2 but at the same time these levels were significantly higher when compared to the controls. Such similarities were observed with HbAlc levels: in diabetic animals they were twice times higher than the controls, while group 3 and 4 had intermediate position (Table 3). 
Table 1. Time-parameters of Ang II- and AVP - provoked uterine contraction after inducing diabetes mellitus, with and without protection.

\begin{tabular}{|c|c|c|c|c|c|c|c|c|}
\hline \multirow{2}{*}{ Group } & \multicolumn{4}{|c|}{ Ang II } & \multicolumn{4}{|c|}{ AVP } \\
\hline & $\mathbf{T}_{\mathrm{hc}}(\mathrm{s})$ & $\mathbf{T}_{\mathrm{c}}(\mathrm{s})$ & $\mathbf{T}_{\mathrm{hr}}(\mathrm{s})$ & $\mathbf{T}_{\mathrm{chr}}(\mathrm{s})$ & $\mathbf{T}_{\mathrm{hc}}(\mathrm{s})$ & $\mathbf{T}_{\mathrm{c}}(\mathrm{s})$ & $\mathbf{T}_{\mathrm{hr}}(\mathrm{s})$ & $\mathbf{T}_{\text {chr }}(\mathrm{s})$ \\
\hline Controls Ph-1 & $9 \pm 1$ & $54 \pm 4 *$ & $81 \pm 8.5^{* \$}$ & $135 \pm 11 *$ & $10 \pm 1$ & $44 \pm 4$ & $164 \pm 14^{*}$ & $208 \pm 17^{*}$ \\
\hline Group 2 Ph-1 & $6 \pm 1$ & $31.5 \pm 5$ & $66 \pm 12$ & $100 \pm 16^{\#}$ & $7 \pm 1$ & $34 \pm 6$ & $33 \pm 6$ & $67 \pm 7$ \\
\hline Group 3 Ph-1 & $5 \pm 1$ & $25 \pm 3$ & $169 \pm 13^{\&}$ & $194 \pm 15^{\&}$ & $7 \pm 1$ & $36 \pm 5$ & $228 \pm 28^{\&}$ & $264 \pm 28^{\&}$ \\
\hline Group 4 Ph-1 & $6 \pm 1$ & $11 \pm 3^{\$}$ & $55 \pm 5$ & $66 \pm 6^{\$}$ & $6 \pm 1$ & $9 \pm 2^{\$}$ & $45 \pm 6$ & $54 \pm 7$ \\
\hline Controls Ph-2 & $9 \pm 2.5$ & $70 \pm 5 *$ & $110 \pm 15^{*}$ & $180 \pm 13$ & $10 \pm 1$ & $47 \pm 7$ & $167 \pm 9$ & $214 \pm 11$ \\
\hline Group 2 Ph-2 & $13 \pm 3$ & $46.5 \pm 7$ & $214 \pm 28$ & $260 \pm 20^{\$}$ & $6 \pm 2$ & $38 \pm 5$ & $204 \pm 29$ & $242 \pm 30$ \\
\hline Group 3 Ph-2 & $11 \pm 2$ & $40 \pm 10$ & $170 \pm 18$ & $211 \pm 26$ & $7.5 \pm 1$ & $23 \pm 4^{\&}$ & $162 \pm 16$ & $185 \pm 17$ \\
\hline Group 4 Ph-2 & $6 \pm 1$ & $11 \pm 2^{\$}$ & $192 \pm 24$ & $203 \pm 24$ & $6 \pm 1$ & $10 \pm 3^{\$}$ & $119 \pm 17^{\$}$ & $129 \pm 20^{\$}$ \\
\hline
\end{tabular}

Ph-1: folicular phase of estrous cycle; Ph-2: luteal phase of estrous cycle. Controls: healthy animals; Group 2: diabetic animals; Group 3: diabetic animals treated with MLT; Group 4: diabetic animals treated with GHR. $* P<0.05$ vs. groups $2-4, * \$ p<0.05$ vs. group 4, ${ }^{\#} P<0.05$ vs. controls and groups 3 and $4,{ }^{\&} P<0.05$ vs. controls and groups 2 and $4, \$ p<0.05$ vs. controls and groups 2 and 3 .

Table 2. Registered data for systolic and diastolic blood pressure and body weight from the beginning and the end of experimental period.

\begin{tabular}{|c|c|c|c|c|c|c|}
\hline Group & $\begin{array}{c}\text { Systolic Blood } \\
\text { Pressure } \\
\text { start } \\
\text { (mmHg) }\end{array}$ & $\begin{array}{l}\text { Systolic } \\
\text { Blood } \\
\text { Pressure } \\
\text { end } \\
(\mathrm{mmHg})\end{array}$ & $\begin{array}{c}\text { Diastolic } \\
\text { Blood } \\
\text { Pressure } \\
\text { start } \\
\text { (mmHg) }\end{array}$ & $\begin{array}{l}\text { Diastolic Blood } \\
\text { Pressure } \\
\text { end } \\
(\mathrm{mmHg})\end{array}$ & $\begin{array}{c}\text { Body } \\
\text { Weight } \\
\text { start } \\
\text { (g) }\end{array}$ & $\begin{array}{c}\text { Body } \\
\text { Weight } \\
\text { end } \\
\text { (g) }\end{array}$ \\
\hline Controls & $126 \pm 4$ & $122 \pm 3$ & $92 \pm 2$ & $90 \pm 3$ & $335 \pm 8$ & $375 \pm 20 * *$ \\
\hline Group 2 & $123.5 \pm 2.5$ & $120 \pm 5$ & $91 \pm 3$ & $86 \pm 4$ & $345 \pm 6$ & $271 \pm 13 * *$ \\
\hline Group 3 & $129 \pm 6$ & $139 \pm 4.5^{*}$ & $96 \pm 6$ & $111.5 \pm 4.5^{*}$ & $323 \pm 6$ & $328 \pm 19$ \\
\hline Group 4 & $137.5 \pm 2$ & $132.5 \pm 5.5$ & $108 \pm 5$ & $108 \pm 4.5$ & $331 \pm 10$ & $331 \pm 24$ \\
\hline
\end{tabular}

Controls: healthy animals; Group 2: diabetic animals; Group 3: diabetic animals treated with MLT; Group 4: diabetic animals treated with GHR. * $P<0.05$ vs. blood pressure in the beginning of the experiment, $* * P<0.05$ vs. body weight in the beginning of the experiment.

Table 3. Registered data of glycemic status from the experimental groups of rats.

\begin{tabular}{lccccc}
\hline Group & $\begin{array}{c}\text { Glucose start } \\
(\mathbf{m m o l} / \mathbf{l})\end{array}$ & $\begin{array}{c}\text { Glucose } \\
\mathbf{7 2 - h} \\
(\mathbf{m m o l} / \mathbf{l})\end{array}$ & $\begin{array}{c}\text { Glucose } \\
\text { end } \\
(\mathbf{m m o l} / \mathbf{l})\end{array}$ & $\begin{array}{c}\text { HbA1c } \\
\text { start } \\
\mathbf{( \% )}\end{array}$ & $\begin{array}{c}\text { HbA1c } \\
\text { end } \\
(\mathbf{\%})\end{array}$ \\
\hline Controls & $6.59 \pm 0.3$ & $6.45 \pm 0.36$ & $6.53 \pm 0.34$ & $2.22 \pm 0.16$ & $2.11 \pm 0.14$ \\
Group 2 & $6.87 \pm 0.4$ & $29.4 \pm 1.99$ & $30.76 \pm 1.1^{\#}$ & $2.04 \pm 0.16$ & $4.75 \pm 0.39^{\#}$ \\
Group 3 & $7.45 \pm 0.23$ & $28.67 \pm 1.94$ & $22.87 \pm 3.87^{*}$ & $2.09 \pm 0.28$ & $3.4 \pm 0.15^{*}$ \\
Group 4 & $6.92 \pm 0.16$ & $21.52 \pm 3.19$ & $13.92 \pm 0.70^{* *}$ & $2.28 \pm 0.16$ & $3.46 \pm 0.24^{*}$ \\
\hline
\end{tabular}

Controls: healthy animals; Group 2: diabetic animals; Group 3: diabetic animals treated with MLT; Group 4: diabetic animals treated with GHR. * $P<0.05$ vs. Controls, $* * P<0.05$ vs. Controls, ${ }^{\#} P<0.05$ vs. controls and groups 3 and 4 . HbA1c - glycated hemoglobin. 


\section{Discussion}

The experimentally induced DM influenced negatively the peptide-mediated uterine contractile activity. The chronic hyperglycemia affected equally the power characteristics of Ang II- and AVP-provoked responses. These disorders were probably due to the neuropathy, the damage of the pacemaker cells, and the myopathy caused by the hyperglycemia (Szarka and Camilleri 2010). The reduced calmodulin levels and ROS-induced $\mathrm{Ca}^{2+}$-desensitization in different smooth muscle organs (Ozturk et al. 1997, Suzuki et al. 2011), obviously affected also uterus.

During the phase 1 of estrous cycle the diabetic UH preparations developed better response to Ang II and AVP. Heaton et al. (1992) described higher and more frequent uterine contractions when intracellular environment was alkalized. Based on this research, it can be assumed that the better endometrial and myometrial blood supply during the follicular phase contributes to a recovered acid-base balance and improved uterine response to the applied peptides. Appiah et al. (2009), found that $\mathrm{H}_{2} \mathrm{O}_{2}$ leads to a dose-dependent decrease of uterine contractions. According to them, the vanishing of the toxic effect of radical damage on myometrium caused by the improved blood circulation probably leads to a better contractile response. During phase $1 \mathrm{UH}$ preparations from diabetic animals (group 2) showed lower values of $\mathrm{T}_{h r}$ and $\mathrm{T}_{\text {chr }}$ compared to controls, while in phase 2 , the same parameters were highly prolonged. The reason for these differences could be connected with nitric oxide (NO) production. In experimentally-induced DM in rats Ozçelikay et al. (2000) have established an endothelium-dependent inhibition of arterial vessel relaxation as a result of ROS action. Rudichenko and Beierwaltes (1995) also prove that the paradoxical vasodilator effect of AVP in brain and kidney vessels is due to NO synthesis by endothelial cells. It is reasonable to believe that during phase 2 NO synthesis is strongly influenced, while during phase 1 the produced NO, as a consequence of hypertrophy, leads to much faster relaxation of smooth musculature.

In addition, the found changes in body weight, plasma levels of glucose and HbAlc were evidence for an impaired pancreatic B-cell function in the animals from group 2.

\section{Melatonin and experimentally-induced DM}

Seven-day administration of MLT in diabetic animals had beneficial effect on UH preparations produced during phase 2 of the estrous cycle. Our results are in accordance to Turgut and Kaplan (2011), who establish that the additional administration of MLT in animals with experimental DM leads to a strong restorative effect. The beneficial effect of MLT on smooth muscle contractility is multifactorial. On one hand, MLT improves glycemic profile by expression of MLT type 2 receptors on B-cells of the pancreas, thus promoting secretion of insulin (Javorek et al. 2012). MLT also leads to a better utilization of glucose by muscle cells (Espino et al. 2011). On the other hand, MLT has a strong antioxidant effect and helps trapping a large number of ROS. A possible regeneration of damaged neural structures which support the normal function of visceral organs has also been discussed (Odaci and Kaplan 2009).

Significantly prolonged relaxation parameters of SMCs of UH preparations made during phase 1 are consistent with data from Geary et al. (1998) that MLT can block $\mathrm{Ca}^{2+}$-dependent $\mathrm{K}^{+}$-channels, thus contributing to a slow relaxation. The transient increase of beta-estradiol blood levels may also result in decreased expression of the maxi- $\mathrm{K}^{+}$-channels, which is another explanation for the long-lasting relaxation (Korovkina et al. 2004).

The study of glycemic parameters also indicated a protective effect of MLT on B-cell function. These results are supported by a number of authors (Montilla et al. 1998, Guven et al. 2006). The powerful antioxidant effect of MLT is considered to be the main factor that reduces cell death and apoptosis, caused by STZ. In addition, MLT decreases the expression of GLUT2 transporters, thus preventing STZ entrance in B-cells, which is evident by the improved glycemic profile and preserved body mass of experimental animals.

Group 3 was the only one that showed elevated values of blood pressure in the end of the experimental period. These results were in conflict with the data about the pronounced antihypertensive effect of MLT (Grossman et al. 2011). On the other hand, the results can be explained with the described from Tamura et al. (2006) inhibiting effect of MLT on endothelial nitric oxide synthase (eNOS). According to the authors, this effect is not mediated by classical MLT receptors.

\section{Ghrelin and experimentally-induced DM}

Similarly to group 3, UH preparations from animals treated with GHR, developed Ang II- and 
AVP-induced contractions with improved power characteristics when compared to group 2, especially from phase 2 of the estrous cycle. These results and the best glycemic profile of the group when compared to the other two diabetic groups are in agreement with the results of Granata et al. 2010. The authors reported about protective and antioxidant properties of GHR and the inhibition of apoptosis. In accordance with the observations of Kerem et al. (2009), we also assume that GHR contributes to the regeneration of the pancreas.

The rapid achievement of $T_{c}$ and the development of very fast relaxation in Ang II- and AVP-mediated contractions of preparations from group 4 may be due to a direct effect of GHR on the smooth muscle tone. According to Qiu et al. (2008) and Asakawa et al. (2001), in experimentally induced diabetes followed by administration of GHR, an increased spontaneous activity was registered, due to the activation of peripheral cholinergic pathways.

\section{Conclusion}

Experimentally induced DM had a pronounced negative effect on the development of Ang II- and
AVP-stimulated uterine SMCs, leading to reduced smooth muscle activity probably due to formation and accumulation of glycated products and ROS. The seven-day administration of MLT $(10 \mathrm{mg} / \mathrm{kg})$ or GHR $(100 \mu \mathrm{g} / \mathrm{kg})$ had a beneficial effect on diabetic animals and partially improved the response of UH preparations to Ang II and AVP by reducing ROS, protein glycation and partial regeneration of the pancreas. MLT has primary antioxidant effect, while GHR possess reparative properties. Both hormones have a direct effect on the development of SMC. The application of MLT in diabetic animals increased both force and time-parameters of Ang II- and AVP-stimulated uterine contractions while treatment with GHR increased power characteristics and shortened contraction and relaxation of the smooth muscle process.

\section{Conflict of Interest}

There is no conflict of interest.

\section{Acknowledgements}

This study was supported by Grant 25/2014 from Medical Faculty, Trakia University, Stara Zagora, Bulgaria.

\section{References}

ABU EL-ASRAR AM: Evolving strategies in the management of diabetic retinopathy. Middle East Afr J Ophthalmol 20: 273-282, 2013.

AGUILAR HN, MITCHELL BF: Physiological pathways and molecular mechanisms regulating uterine contractility. Hum Reprod Update 16: 725-744, 2010.

AISAIF S, MUMTAZ S, WRAY S: A short review of adipokines, smooth muscle and uterine contractility. Life Sci 125: $2-8,2015$.

APPIAH I, MILOVANOVIC S, RADOJICIC R: Hydrogen peroxide affects contractile activity and anti-oxidant enzymes in rat uterus. Br J Pharmacol 158: 1932-1941, 2009.

ASAKAWA A, INUI A, KAGA T, YUZURIHA H, NAGATA T, UENO N: Ghrelin is an appetite-stimulatory signal from stomach with structural resemblance to motilin. Gastroenterol 120: 337-345, 2001.

CHANG MJ, XIAO JH, WANG Y, YAN YL, YANG J, WANG JL: 2, 3, 5, 4'-tetrahydroxystilbene-2-O-beta-Dglucoside improves gastrointestinal motility disorders in STZ - induced diabetic mice. PLoS One 7: e50291, 2012.

CHATZIGEORGIOU A, HALAPAS A, KALAFATAKIS K, KAMPER E: The use of animal models in the study of diabetes mellitus. In Vivo 23: 245-258, 2009.

ESPINO J, PARIENTE JA, RODRÍGUEZ AB: Role of melatonin on diabetes-related metabolic disorders. World J Diabetes 2: 82-91, 2011.

FALKAY G, SPIEGL G, CSONKA D, ZUPKÓ I: Effects of streptozotocin-induced diabetes on the uterine adrenergic nerve function in pregnant rats. A superfusion study. Neurochem Int 51: 306-310, 2007.

GEARY GG, DUCKLES SP AND KRAUSE DN: Effect of melatonin in the rat tail artery: role of K+ channels and endothelial factors. Br J Pharmacol 123: 1533-1540, 1998. 
GEORGIEV T, HADZHIBOZHEVA P, TOLEKOVA A: Contractile responses of the rat uterine smooth muscle to influences with Angiotensin II and Vasopressin. Scr Sci Med 44 (Suppl 1): 93-96, 2012.

GRANATA R, VOLANTE M, SETTANNI F, GAUNA C, GHÉ C, ANNUNZIATA M, DEIDDA B, GESMUNDO I, ABRIBAT T, VAN DER LELY AJ, MUCCIOLI G, GHIGO E, PAPOTTI M: Unacylated ghrelin and obestatin increase islet cell mass and prevent diabetes in streptozotocin-treated newborn rats. J Mol Endocrinol 45: 9-17, 2010.

GROSSMAN E, LAUDON M, ZISAPEL N: Effect of melatonin on nocturnal blood pressure: meta-analysis of randomized controlled trials. Vasc Health Risk Manag 7: 577-584, 2011.

GUVEN A, YAVUZ O, CAM M, ERCAN F, BUKAN N, COMUNOGLU C, GOKCE F: Effects of melatonin on streptozotocin-induced diabetic liver injury in rats. Acta Histochem 108: 85-93, 2006.

HEATON RC, TAQQART MJ, WRAY S: The effect of intracellular and extracellular alkalinization on contractions of the isolated rat uterus. Pflugers Arch 422: 24-30, 1992.

HEHIR MP, GLAVEY SV, MORRISON JJ: Uterorelaxant effect of ghrelin on human myometrial contractility. Am J Obstet Gynecol 198: 323.e1-323.e5, 2008.

JAWOREK J, SZKLARCZYK J, JAWOREK AK, NAWROT-PORĄBKA K, LEJA-SZPAK A, BONIOR J, KOT M: Protective effect of melatonin on acute pancreatitis. Int J Inflam 2012: 173675, 2012.

KEREM M, SALMAN B, OZSOY S, PASAOGLU H, BEDIRLI A, HAZIROGLU R, YILMAZ TU: Exogenous ghrelin enhances endocrine and exocrine regeneration in pancreatectomized rats. J Gastrointest Surg 13: 775-783, 2009.

KESKIL Z, BAYRAM M, ERCAN Z, TÜRKER R: The contribution of nitric oxide and endothelins to angiotensin: II. Evoked responses in the rat isolated uterus smooth muscle. Gen Pharmacol 33: 307-312, 1999.

KOROVKINA VP, BRAINARD AM, ISMAIL P, SCHMIDT TJ, ENGLAND SK: Estradiol binding to maxi-K channels induces their down-regulation via proteasomal degradation. J Biol Chem 279: 1217-1223, 2004.

MONTILlA PL, VARQAS JF, TÚNEZ IF, MUÑOZ DE AGUEDA MC, VALDELVIRA ME, CABRERA ES: Oxidative stress in diabetic rats induced by streptozotocin: protective effects of melatonin. J Pineal Res 25 : 94-100, 1998.

O'BRIEN M, EARLEY P, MORRISON JJ, SMITH TJ: Ghrelin in the human myometrium. Reprod Biol Endocrinol 8: $55,2010$.

ODACI E, KAPLAN S: Chapter 16: Melatonin and nerve regeneration. Int Rev Neurobiol 87: 317-335, 2009.

OLCESE J, BEESLEY S: Clinical significance of melatonin receptors in the human myometrium. Fertil Steril 102: 329-335, 2014.

OZÇELIKAY AT, TAY A, GÜNER S, TAŞYARAN V, YILDIZOĞLU-ARI N, DINÇER UD, ALTAN VM: Reversal effects of L-arginine treatment on blood pressure and vascular responsiveness of streptozotocin-diabetic rats. Pharmacol Res 41: 201-209, 2000.

OZTURK Y, AYDIN S, OZCELIKAY AT, ALTAN VM, YALDIZOGLU-ARI N: Calmodulin content and in vitro contractility of duodenum from streptozotocin-induced diabetic rats: effects of insulin therapy and calmodulin antagonism. Eur J Pharmacol 31: 59-65, 1997.

QIU WC, WANG ZG, LV R, WANG WG, HAN XD, YAN J, WANG Y, ZHENG Q, AI KX: Ghrelin improves delayed gastrointestinal transit in alloxan-induced diabetic mice. World J Gastroenterol 14: 2572-2577, 2008.

RUDICHENKO VM, BEIERWALTES WH: Arginine vasopressin-induced renal vasodilation mediated by nitric oxide. $J$ Vasc Res 32: 100-105, 1995.

SHPAKOV AO, DERKACH KV, CHISTIAKOVA OV, MOǏSEIUK IV, SUKHOV IB, BONDAREVA VM: Effects of intranasal insulin and serotonin on functional activity of the adenylyl cyclase system in the myocardium, ovaries, and uterus of rats with prolonged neonatal model of diabetes mellitus. Zh Evol Biokhim Fiziol 49: 118-127, 2013.

STAMLER J, VACCARO O, NEATON JD: Diabetes, other risk factors, and 12-yr cardiovascular mortality for men screened in the Multiple Risk Factor Intervention Trial. Diabetes Care 16: 434-444, 1993. 
STEINWALL M, BOSSMAR T, BROUARD R, LAUDANSKI T, OLOFSSON P, URBAN R, WOLFF K, LE-FUR G, AKERLUND M: The effect of relcovaptan (SR 49059), an orally active vasopressin V1 a receptor antagonists on uterine contractions in preterm labor. Gynecol Endocrinol 20: 104-109, 2005.

SUZUKI H, MATSUZAKI J, HIBI T: Ghrelin and oxidative stress in gastrointestinal tract. J Clin Biochem Nutr 48: 122-125, 2011.

SZARKA LA, CAMILLERI M: Stomach dysfunction in diabetes mellitus: emerging technology and pharmacology. J Diabetes Sci Technol 4: 180-189, 2010.

TAMURA EK, SILVA CLM, MARKUS RP: Melatonin inhibits endothelial nitric oxide production in vitro. $J$ Pineal Res 41: 267-274, 2006.

TOLEKOVA AN, HADZHIBOZHEVA PV, ILIEV RN, GEORGIEV CK, TRIFONOVA KY, SANDEVA RV, KALFIN RE, ILIEVA GS: Participation of extracellular $\mathrm{Ca}(2+)$ or ghrelin in peptide-mediated contraction of strips from rat urinary bladder. Regul Pept 162: 79-83, 2010.

TURGUT M, KAPLAN S: Effects of melatonin on peripheral nerve regeneration. Recent Pat Endocr Metab Immune Drug Discov 5: 100-108, 2011.

VURAL H, SABUNCU T, ARSLAN SO, AKSOY N: Melatonin inhibits lipid peroxidation and stimulates the antioxidant status of diabetic rats. J Pineal Res 31: 193-198, 2001.

WRAY S: Insights into the uterus. Exp Physiol 92: 621-631, 2007.

YANKOV K: Assessment of characteristic parameters of oscillating models. In: Proc Int Conf Inform Technol (InfoTech-2012). 2012, pp 114-123.

YANKOV K: Preprocessing of experimental data in Korelia Software. Trakia J Sci 8: 41-48, 2010. 